Review

\title{
Far Beyond the Usual Biomarkers in Breast Cancer: A Review
}

\author{
Brunna dos Anjos Pultz ${ }^{1}$, Felipe Andrés Cordero da Luz ${ }^{1}$, Paulo Rogério de Faria², Ana Paula Lima \\ Oliveira$^{2}$, Rogério Agenor de Araújo ${ }^{3}$, and Marcelo José Barbosa Silva ${ }^{1 凶}$ \\ 1. Laboratório de Imunoparasitologia, Universidade Federal de Uberlândia, Uberlândia, Minas Gerais, Brazil. \\ 2. Laboratório de Histologia, Universidade Federal de Uberlândia, Uberlândia, Minas Gerais, Brazil. \\ 3. Setor de Oncologia - Hospital de Clínicas de Uberlândia, Uberlândia, Minas Gerais, Brazil.
}

$\triangle$ Corresponding author: Marcelo José Barbosa Silva, Pará Avenue, 1720 - Build 4c. Immunology Laboratory. Uberlândia. MG, CEP 38400-902 - CP 592. Phone: +553432182195 Fax: +55343218-2247 majbsilva@gmail.com.

(c) Ivyspring International Publisher. This is an open-access article distributed under the terms of the Creative Commons License (http://creativecommons.org/ licenses/by-nc-nd/3.0/). Reproduction is permitted for personal, noncommercial use, provided that the article is in whole, unmodified, and properly cited.

Received: 2014.02.25; Accepted: 2014.04.10; Published: 2014.07.04

\begin{abstract}
Research investigating biomarkers for early detection, prognosis and the prediction of treatment responses in breast cancer is rapidly expanding. However, no validated biomarker currently exists for use in routine clinical practice, and breast cancer detection and management remains dependent on invasive procedures. Histological examination remains the standard for diagnosis, whereas immunohistochemical and genetic tests are utilized for treatment decisions and prognosis determinations. Therefore, we conducted a comprehensive review of literature published in PubMed on breast cancer biomarkers between 2009 and 2013. The keywords that were used together were breast cancer, biomarkers, diagnosis, prognosis and drug response. The cited references of the manuscripts included in this review were also screened. We have comprehensively summarized the performance of several biomarkers for diagnosis, prognosis and predicted drug responses of breast cancer. Finally, we have identified 15 biomarkers that have demonstrated promise in initial studies and several miRNAs. At this point, such biomarkers must be rigorously validated in the clinical setting to be translated into clinically useful tests for the diagnosis, prognosis and prediction of drug responses of breast cancer.
\end{abstract}

Key words: breast cancer; biomarkers; early diagnosis; prognosis; chemotherapy resistance.

\section{INTRODUCTION}

Human breast cancer is a major cause of morbidity and mortality in women all over the world. Data from the International Agency for Research on Cancer (IARC) showed that the incidence of cancer has increased all over the world. Regarding breast cancer, the highest incidence rates were found in the United States and Western Europe with 101 and 85 new cases per 100.000 women, respectively. East Asia has the lowest rate, representing 21 cases per 100,000 women. In Africa, the incidence is reported to be 23 per 100,000 women, but, due to lack registries and accurate data, this rate may be underestimated [1].

In 2013, the American Cancer Society estimates that more than 230,000 Americans women will be diagnosed with this neoplasia and that more than 40,000 will die of this disease in the United States [2]. This estimate is alarming, and it is estimated that more than 1 million new cases will be diagnosed worldwide [1].

An additional factor that contributes to the poor prognosis of patients diagnosed with breast cancer is the fact that the diagnosis is often delayed due to limitations in mammography. Screen-film mammography (SFM) is considered the gold standard for breast cancer screening and detection [3]. However, its optimal performance is only observed among women 
over 50 years old [4]. Also, SFM has other limitations such high rates of false-negative, between $4-34 \%$, high rate of false-positive, leading to unnecessary biopsy procedures and is less sensitive in women with dense breast tissue [5]. Available alternative to SFM includes full-field digital mammography (FFDM) which is slightly more sensitive in younger women with dense breasts [6]. However, there are limitations that must be overcome to improve the screening and detection of breast cancer.

The main factor that contributes to breast cancer mortality is the presence of metastasis, which is the leading cause of mortality and accounts for more than 400,000 deaths annually around the world $[1,7]$. Of those diagnosed with breast cancer, $30 \%$ to $85 \%$ of these patients are diagnosed with bone metastases, and the median survival rate after diagnosis is 25 to 72 months $[8,9]$. When the cancer involves viscera, the prognosis is worse and survival is shorter.

Another factor associated with increased mortality and relapse rates is the development of resistance to chemotherapeutics. For almost three decades, tamoxifen has been the mainstay of endocrine therapy for the treatment of hormone-receptorpositive breast cancer in pre-menopausal women and is also frequently used by post-menopausal women, both in early or advanced breast cancer [10]. It has been estimated that approximately $50 \%$ of breast cancer patients undergoing chemotherapy develop tamoxifen resistance [11]. Recent study showed that about $20 \%$ of post-menopausal breast cancer patients who received tamoxifen in first line of therapy develop resistance and were considered non-responders to treatment [12]. Some studies have shown that more than one-third of patients with metastatic breast cancer do not respond to first-line anthracyclines or taxanes, and disease progression occurs in less than 1 year, leading to the death of more than $90 \%$ of patients with metastatic breast cancer [13-15].
Thus, given the considerable public health importance of breast cancer, it is crucial to quickly identify new biomarkers with the potential to enhance early diagnosis and to predict patient prognosis, drug resistance development and treatment choice. Despite the large number of published articles on breast cancer biomarkers, a reliable marker for use in clinical practice remains unavailable.

A PubMed search with the keywords "breast cancer, biomarkers, diagnosis, prognosis and drug response" published from 2009 to 2013 was conducted resulting in 852 papers. A specific filter for selection of the papers with abstract and full text available was applied resulting in 311 publications. The titles and abstracts were reviewed and selected. Studies were excluded from the review if the abstract provided was insufficient for the primary regarding breast cancer diagnosis, prognosis and drug response for the biomarker under study. Then, all selected papers were read completely for initial analysis and discussed with all co-authors of this manuscript. After the discussion, all biomarkers selected were included in this paper. Additionally, other studies cited in selected manuscripts were consulted in PubMed and included in this review.

We summarized the performance of several biomarkers for enhancing the diagnosis, prognosis and predicting drug responses of breast cancer. Also, we synthesized all biomarkers described in a table regarding the importance of biomarker, references of studies that supported this article, type of sample used in the study and the date of sample collection (table 1). So, this review focuses biomarkers that have demonstrated promise in initial studies and now must be rigorously validated in the clinical setting to be translated into clinically useful tests for diagnosing, prognosing and predicting the response of breast cancer to various drug therapies.

Table I. This table synthesized all biomarkers described regarding the importance of biomarker, references of main studies that supported this review, type of sample used in the study and the date of sample collection.

\begin{tabular}{|c|c|c|c|c|c|}
\hline Biomarkers & Importance of biomarker & Reference & Number of participants & Sample & Date of sample collection \\
\hline \multirow[t]{2}{*}{$\mathrm{uPA}+\mathrm{PAI}+\mathrm{TF}$} & Diagnosis & [21] & 79 & Nipple discharge & $2008-2010$ \\
\hline & & [24] & 260 & Peripheral blood & NS \\
\hline \multirow[t]{5}{*}{ h-MAM } & Diagnosis/ Prognosis & [25] & 102 & Peripheral blood & NS \\
\hline & & [26] & 98 & Peripheral blood & $2007-2010$ \\
\hline & & [27] & 112 & Bone marrow & $2000-2003$ \\
\hline & & [28] & 833 & Breast biopsies & NS \\
\hline & & [34] & 375 & Breast biopsies & 2006-2010 \\
\hline \multirow[t]{4}{*}{ Osteopontin } & Prognosis & [36] & - & Mouse/ cell culture & - \\
\hline & & [39] & 200 & Breast biopsies & 2001-2002 \\
\hline & & [41] & - & Cell culture & - \\
\hline & & [42] & 667 & $\begin{array}{l}\text { Breast biopsies/ } \\
\text { Peripheral blood }\end{array}$ & $1996-2000$ \\
\hline \multirow[t]{2}{*}{ FGFR2 } & Prognosis & [46] & 26 & Breast biopsies & NS \\
\hline & & [47] & - & Cell culture & - \\
\hline PTEN & Prognosis & [52] & 78 & Breast biopsies & NS \\
\hline
\end{tabular}




\begin{tabular}{|c|c|c|c|c|c|}
\hline & & [53] & 146 & Breast biopsies & $2003-2006$ \\
\hline \multirow{2}{*}{ Sirtuins } & \multirow[t]{2}{*}{ Prognosis } & [56] & 46 & Breast biopsies & $1993-2005$ \\
\hline & & [57] & 74 & Breast biopsies & NS \\
\hline \multirow[t]{2}{*}{ Snail 1} & \multirow[t]{2}{*}{ Prognosis } & [63] & 21 & Breast biopsies & NS \\
\hline & & [64] & 30 & Breast biopsies & NS \\
\hline Twist & Prognosis & [64] & 30 & Breast biopsies & NS \\
\hline \multirow[t]{2}{*}{ Zeb-1 } & \multirow[t]{2}{*}{ Prognosis } & {$[65]$} & - & Mouse/ cell culture & - \\
\hline & & {$[71]$} & 393 & Peripheral blood & NS \\
\hline \multirow[t]{2}{*}{ CYP2D6 } & \multirow{2}{*}{$\begin{array}{l}\text { Prediction of drug re- } \\
\text { sponses }\end{array}$} & {$[72]$} & 90 & Peripheral blood & NS \\
\hline & & [73] & 4861 & Breast biopsies & $1998-2003$ \\
\hline \multirow[t]{3}{*}{ PIK3CA } & \multirow{3}{*}{$\begin{array}{l}\text { Prediction of drug re- } \\
\text { sponses }\end{array}$} & {$[78]$} & - & Mouse & - \\
\hline & & [79] & 80 & Breast biopsies & $2004-2007$ \\
\hline & & {$[80]$} & 1352 & Peripheral blood & $1978-2007$ \\
\hline \multirow[t]{2}{*}{ RARA } & \multirow[t]{2}{*}{$\begin{array}{l}\text { Prediction of drug re- } \\
\text { sponses }\end{array}$} & {$[86]$} & - & Cell culture & - \\
\hline & & [89] & - & Cell culture & - \\
\hline \multirow[t]{2}{*}{ STAT3 } & \multirow[t]{2}{*}{$\begin{array}{l}\text { Prediction of drug re- } \\
\text { sponses }\end{array}$} & {$[90]$} & 8 & $\begin{array}{l}\text { Breast biopsies/ Cell } \\
\text { culture }\end{array}$ & NS \\
\hline & & {$[96]$} & 99 & Breast biopsies & $2005-2008$ \\
\hline \multirow[t]{3}{*}{ TIMP-1 } & \multirow{3}{*}{$\begin{array}{l}\text { Prediction of drug re- } \\
\text { sponses }\end{array}$} & {$[97]$} & - & Cell culture & - \\
\hline & & [98] & - & Cell culture & - \\
\hline & & [99] & - & Cell culture & - \\
\hline \multirow[t]{2}{*}{$\operatorname{Lin} 28$} & \multirow{2}{*}{$\begin{array}{l}\text { Prediction of drug re- } \\
\text { sponses }\end{array}$} & [103] & 9 & $\begin{array}{l}\text { Breast biopsies/ Cell } \\
\text { culture }\end{array}$ & $2002-2010$ \\
\hline & & [104] & - & Cell culture & - \\
\hline
\end{tabular}

NS = Not Shown .

\section{POTENTIAL BIOMARKERS FOR THE DIAGNOSIS AND PROGNOSIS OF BREAST CANCER}

Detection of breast cancer at an early stage via a biomarker assay is extremely important to reduce the burden of disease because breast cancer detected at an earlier stage is much more curable than metastatic disease. Thus, it is also necessary to identify biomarkers that may predict the occurrence of metastasis before it manifests in the patient. Based on this requirement, several potential biomarkers have gained attention and are described below: 1. The combination of three independent biomarkers, including the urokinase-dependent plasminogen activator system (uPA), the plasminogen activator inhibitor (PAI) and the Thomsen-Friedenreich (TF) antigen for an early diagnosis. 2. Mammaglobin, osteopontin, snail, twist, Zeb-1, fibroblast growth factor receptors (FGFR), phosphatase and tensin homolog (PTEN) and sirtuins (SIRT) are potential biomarkers for the prediction of metastatic disease.

\section{UPA, PAI and TF}

An optimal combination of well-known biomarkers has attracted the attention of researchers. The serine protease uPA is a tumor-associated protease that appears to play a role in both invasion and metastasis in solid tumors. UPA and its inhibitor, PAI-1, were the first tumor markers to have your clinical value confirmed in studies with level of evidence 1 (evidences based on randomized clinical trials or meta-analysis of clinical trials with high recom- mendation for treatment decisions) and are prognostic factors independent of traditionally used factors. Therefore, uPA and its inhibitor, PAI-1 could be suitable for the routine assessment of prognosis in breast cancer patients [16]. Their overexpression in tumor tissue is associated with an increased risk of relapse and reduced survival [17]. TF antigen is an aberrantly glycosylated carbohydrate and cancer-associated antigen found in approximately $80 \%$ of adenocarcinomas, including breast cancer [18]. TF has been shown to be involved in tumor cell adhesion and migration [19].

The uPA concentration was more predictive of disease in premenopausal women (83-87\%), while TF antigen was a greater predictor of breast atypia and cancer in postmenopausal women $(81-83 \%)$ [20, 21]. However, the combination of both TF and uPA biomarkers in nipple aspirate fluid predicted breast cancer in both pre- and postmenopausal women with $84-92 \%$ accuracy [21]. When used in combination with uPA, PAI-1 and TF have higher predictive capacities to detect breast cancer and achieved accuracy values of $97-100 \%$ [21] in nipple aspirate fluid. Therefore, large clinical trials are needed to validate the combination of these biomarkers for the early diagnosis of breast cancer.

\section{Mammaglobin}

Watson and Fleming identified the human mammaglobin (h-MAM) gene in 1996 using a differential display PCR technique. Mammaglobin A (MGBA) is a $10-\mathrm{kd}$ protein that is expressed almost exclusively in normal mammary gland epithelium 
and in breast cancer [22, 23]. MGBA expression is higher in the serum of breast cancer patients than in normal controls, indicating that mammaglobin could be potentially used as a serum biomarker for the diagnosis of breast cancer [24]. Galvis-Jiménez generate antibodies against mammaglobin in rabbits using four synthetic peptides, and all antibodies obtained were able to discriminate patients with breast cancer and control. The best antibody had a sensitivity of $86.3 \%$ and specificity of $96 \%$ [25].

Lee and colleagues found that the rate of plasma h-MAM mRNA positivity was $23.4 \%$ in early stages of cancer, while this value increased to $82.9 \%$ in advanced stages. This difference suggests that the detection of plasma h-MAM mRNA appears to be associated with an unfavorable prognosis and a lower rate of event-free survival in breast cancer patients [26].

Additionally, h-MAM may indicate lymph node metastasis. Using RT-PCR techniques, Liu and colleagues evaluated the expression of h-MAM mRNA in the bone marrow (BM) of patients with breast cancer and associated axillary lymph node metastasis. The expression of h-MAM in the BM was higher for the group with axillary lymph node metastasis, $52.5 \%$, than in the group without metastatic disease, $23.5 \%$ [27]. Studies by Luo and colleagues demonstrated that mammaglobin expression was able to detect $72 \%$ of lymph node metastases by immunohistochemistry; when combined with another biomarker, GCDFP-15 (gross cystic disease fluid protein-15), mammaglobin expression detected $83 \%$ of metastases [28]. However, these biomarkers are not useful for the detection of basal-like triple negative breast cancer [29].

It is known that breast cancer cells did not express uniformly the mammaglobin because its expression ranges among different subtypes of tumors. Low-grade and estrogen receptor (ER)-positive tumors express high amount of mammaglobin, while ER-negative and high-grade tumors express lower numbers of mammaglobin mRNA molecules per cell. Thus, a divergence in detection probability may occur for particular types of breast tumors due to enormous variation in the levels of mammaglobin and its association with certain characteristics of the tumor [30].

These results suggest that more studies are needed to validate mammaglobin as a biomarker for diagnosis and lymph node metastasis and, also, it is necessary to consider the tumor characteristics.

\section{Osteopontin}

Osteopontin is a phosphorylated glycoprotein that is able to bind to cell surface integrins, and due to its adhesive properties, hypotheses emerged regarding the role of osteopontin in invasion and metastasis because these processes are dependent on adhesive interactions between tumor cells and the extracellular matrix [31, 32]. A meta-analysis of published literature showed that osteopontin has been associated with 34 cancers, including breast cancer [33]. Recent studies have correlated osteopontin expression with tumor invasion and breast cancer metastasis; thus, the elevated osteopontin level may suggest a more aggressive tumor and a poor prognosis [34, 35]. One study suggests that osteopontin promotes transformation of mesenchymal stem cells into cancer-associated fibroblast which leads to tumor progression, angiogenesis and metastasis [36].

Osteopontin has three splice variants: osteopontin-a, osteopontin-b and osteopontin-c [37]. Osteopontin-c is selectively expressed in breast cancer, and osteopontin-a and osteopontin-b are expressed in both breast cancer and normal breast tissues, making osteopontin-c more useful as a potential marker for breast cancer [38]. In fact, Pang and colleagues demonstrated higher levels of osteopontin-c in breast cancer patients compared to control subjects, and elevated osteopontin-c expression is correlated with lymph node metastasis, advanced stage and tumor recurrence $[39,40]$.

Recent reports also indicate that osteopontin is critical for the epithelial-mesenchymal transition through the activation of Twist following serine phosphorylation, which induces an aggressive breast cancer phenotype [41].

It's well documented that elevated osteopontin levels in tumor tissue and blood are associated with poor outcome in the setting of metastatic breast cancer. However much less is known about the prognostic significance of osteopontin in early breast cancer and during breast cancer progression.

In this sense, a group of researchers from Canada evaluated the prognostic significance of osteopontin in 667 postmenopausal women with hormone responsive early breast cancer in a randomized trial and found no correlation between osteopontin levels and prognostic values, as event-free survival, relapse-free survival (RFS), overall survival, bone RFS or non-bone RFS, but found elevated osteopontin levels around the time of recurrence [42].

This indicates that osteopontin could be a potential biomarker for monitoring the presence of metastasis and more studies are needed to assess its potential for following up the recurrence.

\section{FGFR2}

The fibroblast growth factor receptor (FGFR) family includes four well-known receptors. These receptors have a tyrosine-kinase intracellular domain and are able to homo- or heterodimerize in the presence of fibroblast growth factor (FGF) ligands. Im- 
portantly, receptors 1-3 have an alternative isoform with a ligand Ig-like domain III (isoforms IIIb and IIIc); these isoforms are expressed differentially in epithelial and mesenchymal cells. The isoforms are also responsible for the differential affinity for FGF binding and FGF specificity [43].

Several studies have analyzed the role of FGFR2 polymorphisms in breast cancer susceptibility, progression, and metastasis. Hunter and colleagues performed a genome-wide association study of breast cancer and genotyped 528,173 single nucleotide polymorphisms (SNPs) in 1,145 cases of invasive breast cancer in postmenopausal white women. They identified a set of four SNPs within intron 2 of FGFR2 that was associated with a high risk of developing breast cancer [44]. Easton and colleagues analyzed 4,398 breast cancer cases and 4,316 controls and validated a set of 30 SNPs in 21,860 cases and 22,578 controls from 22 studies. They identified additional important SNPs in intron 2 of FGFR2 [45].

FGFR2 is associated with tumorigenesis. Kim and colleagues observed that FGFR2 is essential for maintaining tumor-initiating cells (TICs) and for promoting tumorigenicity. Primarily, they isolated CD29high $/$ CD24+ TICs from breast cancer-induced mice and observed high self-renewal potency when these isolated cells were injected into NOD/SCID mice, even when only a small number of cells were injected. Then, they observed that FGFR2 is preferentially expressed in TICs with an approximate 22-fold increase in mRNA levels. Flow cytometry data revealed a 5.4 to 10.2-fold increase in FGFR2 protein expression in TICs. The knockdown and pharmacological inhibition of FGFR2 led to a strong decrease in TIC renewal and tumor growth. Moreover, they observed an increase in FGFR2 mRNA levels (32 to 293 -fold) in 2 of 26 breast cancer samples compared to controls, and the FGFR2-enriched TICs derived from human samples were able to induce substantial tumors in NOD/SCID mice [46]. In vitro assays indicated that high expression of FGFR2 was correlated with elevated proliferation rates, motility and invasiveness in cell lineages [47] derived from metastatic breast cancer [48]. Interestingly, cells expressing high levels of FGFR2 are as invasive as Erbb2-overexpressing cells and metastatic lineages [48].

\section{PTEN}

Phosphatase and tensin homolog (PTEN) is a tumor suppressor gene that is deleted or mutated in many human cancers [49], including breast cancer [50]. The loss of PTEN leads to the loss of apoptosis and cell cycle regulation [51].

A retrospective study of 78 stage I/II postmen- opausal patients that were steroid receptor-positive and treated with adjuvant tamoxifen demonstrated the loss of PTEN in 16/43 (37.2\%) patients with ductal carcinoma and in $9 / 35(25.7 \%)$ patients with lobular carcinoma. Additionally, they observed that $96 \%$ of recurrent patients did not express PTEN, and those that did express PTEN relapsed in only $26.4 \%$ of cases [52]. Interestingly, they also found a positive correlation between PTEN expression and longer relapse-free survival, particularly in ER-positive and PTEN-positive patients [53]. These observations are in agreement with previous work [50]. Zhang and colleagues analyzed samples from 146 breast cancer patients, and they found PTEN expression in only $57.5 \%$ of the malignant samples compared to normal samples, which all expressed PTEN. They observed that the samples not expressing PTEN were correlated with increased tumor size and advanced stage.

\section{Sirtuins}

Sirtuins (SIRT) are a highly conserved family of genes that can be found in organisms ranging from bacteria to humans, and they have been implicated in different physiological processes including longevity, apoptosis, differentiation and resistance to stress responses [54]. In mammalian cells, seven sirtuins have been previously discovered and all of these proteins are localized in distinct subcellular regions. For example, SIRT3, SIRT4 and SIRT5 are localized in the mitochondria; SIRT1, SIRT6 and SIRT7 are found in the nucleus, and SIRT2 is primarily located in the cytosol $[55,56]$. Despite these differences in cellular location, all SIRT proteins are characterized by a conserved SIRT domain that possesses catalytic activity and is responsible for binding to NAD+.

SIRT3, the major mitochondrial deacetylase, is responsible for targeting numerous enzymes involved in different oxidative pathways and it also regulates ATP (adenosine triphosphate) production, metabolism and cell signaling [55]. Furthermore, it has been shown that the loss of SIRT 3 is associated with intracellular ROS (Reactive oxygen species) levels and age-related diseases, including cancers; thus, its classification as a tumor suppressor gene has been suggested [57]. Due to its implication in such biological functions, SIRT 3 has been intensively studied. The current understanding indicates that this molecule may play pivotal roles in the context of tumor biology, as observed in breast cancers, especially in terms of clinical behavior and disease stage. Additionally, a recent report demonstrated that $40 \%$ of breast cancers presented with at least one deleted copy of this gene, reinforcing its involvement in breast tumorigenesis and progression [56]. Other investigators described the same conclusion [57]. With regard to its associa- 
tion with tumor progression and metastasis, a previous report showed that SIRT3 expression was significantly associated with metastasis, and this protein was highly expressed in a set of tumors with positive lymph node involvement, indicating a survival advantage for these tumors [54]. In the same study, no correlation was observed between tumor grade and lymphovascular invasion. Therefore, interestingly, investigating this molecule may lead to the discovery of new proteins that are important for the diagnosis of cancer and that also have the potential to assess the prognosis of those affected by breast cancer, especially their metastatic potential and likely survival rate.

\section{Snail, Twist and Zeb I: factors involved in the epithelial-to-mesenchymal transition and metastasis}

It has been suggested that the epithelial-to-mesenchymal transition (EMT) plays a role in the generation of cancer stem cells (CSCs) that have a greater capacity to invade and metastasize to distant sites via changes in their adhesive properties [58]. It has also been proposed that CSCs are involved in the development of drug resistance [59]. Consequently, the EMT has attracted the attention of researchers.

EMT and its reverse are very important events that are essential to life, especially in developing organisms. The EMT promotes the switch of several epithelial isoforms to mesenchymal isoforms, conferring cell-detachment and motility properties with the loss of E-cadherin and the gain of $\mathrm{N}$-cadherin expression. Importantly, this event is mainly regulated by transcription factors that respond to several intracellular and extracellular signals. The most studied transcription factors with respect to the EMT are Twist, Snail1 and Snail2 [60].

However, the EMT is not only a physiological event. Several studies have observed EMT during cancer progression, particularly during metastasis. Mammary adenocarcinoma cells generally begin the EMT process by losing their epithelial markers and cell-attachment proteins and by acquiring mesenchymal markers, thus increasing their motility and invasiveness potential. This pathological phenomenon leads to a stem-like state, marked by the CD44+/CD24-/low phenotype in several cancers [61, 62].

One publication analyzed Snail1 expression in samples from 21 breast cancer patients who did not receive chemotherapy or radiotherapy. Seventeen samples were classified as infiltrating ductal carcinomas (IDC), and four were classified as infiltrating lobular carcinomas (ILC). In normal cells, Snail1 was not expressed, but it was detected in 8 of the 17 IDCs, which was correlated with a loss of E-cadherin expression. In contrast, Snail1 expression was not observed in any of the ILC samples. Interestingly, most of the grade 3 tumors, more than half of the grade 2 tumors, and none of the grade 1 IDCs expressed Snail1. Furthermore, Snail1 is expressed in poorly differentiated IDCs [63].

Tran and colleagues performed several in vitro assays and determined that Snail1 is necessary for EMT initiation and is responsive to TGF $\beta 1$ (Transforming growth factor beta). TWST1 is also necessary for EMT maintenance. They noted that normal and tumorigenic breast lineages underwent EMT following TGF $\beta 1$ exposure. Additionally, they observed a strong correlation among high TWIST1 mRNA expression, reduced Snail1 mRNA expression and metastatic recurrence in bone marrow-invading tumor cells from 30 stage II or III patients. The cohort study also indicated that a high TWIST1:Snail1 ratio following chemotherapy is therapeutically relevant [64].

Another study showed that ZEB1, a transcription factor also associated with the EMT, was more strongly correlated with the CD44 ${ }^{+} / \mathrm{CD} 24^{-} /$low phenotype than Snail1/2 or TWIST1/2, as observed by both in vitro and in vivo approaches. Importantly, they stated that the overexpression of ZEB1 is capable of inducing the EMT in cells that do not express ZEB1 and that ZEB1 levels are higher in cells undergoing EMT compared to controls. ZEB1 expression is also responsible for conferring motility and invasiveness capabilities [65].

Increasing data have indicated that EMT is responsible for cancer metastasis and drug resistance because it induces the cell to an undifferentiated state, transforming the cell to a drug multiresistant profile and high plasticity. Therefore, these markers (Snail, Twist and Zeb-1) are good markers of EMT for breast cancer and, therefore, markers for metastasis and drug resistance.

\section{POTENTIAL BIOMARKERS FOR SYSTEMIC CHEMOTHERAPY RESISTANCE}

Predictive cancer biomarkers for determining the right treatment for each specific patient at the appropriate time are critically needed. Some potential biomarkers for the prediction of systemic chemotherapy resistance include Cytochrome P450 2D6 (CYP2D6), Phosphatidylinositol-4,5-biphosphonate-3-kinase (PIK3CA), Retinoic acid receptor alpha (RARA), Signal transducer and activator of transcription 3 (STAT3), Tissue inhibitor of metalloproteinase 1 (TIMP-1) and Lin28. 


\section{Cytochrome P450 2D6}

One-third of all patients treated with tamoxifen are diagnosed with a relapse within 15 years of follow-up, which represents a quarter of all patients with breast cancer [66]. Therefore, great efforts have been made to understand the mechanisms of resistance and to identify predictive markers of tamoxifen resistance.

Tamoxifen is a selective estrogen receptor modulator (SERM) that blocks the binding of estrogen to its receptor, and it is used to treat breast tumors that express estrogen receptor. However, Tamoxifen itself binds weakly to the estrogen receptor and is considered a prodrug. Thus, to perform its function, it must be metabolized into potent anti-estrogenic metabolites by several cytochrome P450 enzymes [67]. Endoxifen is now considered to be the most important metabolite of Tamoxifen, and it is produced almost exclusively by the activity of cytochrome P450 2D6 (CYP2D6) [68].

The CYP450 genes are polymorphic, resulting in different phenotypes that have been conventionally divided according to their enzymatic activity into poor metabolizers (PM), intermediate metabolizers (IM), extensive metabolizers (EM) and ultra-rapid metabolizers (UM) [69]. The different enzymatic activities might explain some of the clinical variability in the plasma concentrations of Tamoxifen and its metabolites among different patients [70]. Given the importance of CYP2D6 in the metabolism of tamoxifen, many studies have been conducted on its activity in cancer.

Studies have shown that some genetic variants of CYP2D6 are associated with lower concentrations of endoxifen, the active metabolite of Tamoxifen, which could potentially affect the clinical outcome of breast cancer patients following tamoxifen treatment [71, 72].

However, one study conducted by Breast International Group 1-98 trial investigated the clinical relevance of CYP2D6 polymorphisms and found no association between CYP2D6 metabolism phenotypes and breast cancer-free interval among patients who received tamoxifen monotherapy without previous chemotherapy, suggesting that pharmacogenetic testing of CYP2D6 is not useful to determine whether to treat postmenopausal breast cancer patients with tamoxifen [73]. However, this study was questioned by Stanton Jr., Pharoah et al. and Nakamura et al. by presenting highly implausible CYP2D6 genotyping results that raise serious doubt about the conclusions. For example, genotyping was performed from formalin-fixed paraffin-embedded (FFPE) tumor tissue which may compromise the viability of the extracted DNA, especially with a complex gene like CYP2D6 that exhibits copy number variation and is flanked by two highly similar pseudogenes.

Therefore, the patient's CYP2D6 genotype might be used as a potential biomarker for predicting their tamoxifen response and a large-scale, prospective, randomized, well-controlled trial is justified to confirm these findings.

\section{PIK3CA}

Phosphatidylinositol-4,5-biphosphonate 3-kinase (PIK3CA) is the alpha catalytic subunit in the PI3K/PTEN/Akt signaling pathway and controls cell growth, proliferation, motility, survival, differentiation and intracellular trafficking. PIK3CA is the most frequently mutated oncogene in all human cancers [74].

One clinical prospective study analyzed circulating tumor DNA from 52 breast cancer patients, 30 of whom had genomic alterations. These 30 patients had metastatic breast cancer and received systemic therapy. Blood samples were collected over 2 years at an interval of every 3 weeks or more. They observed that 25 of the 52 patients had PIK3CA mutations. Additionally, they found a correlation between drug therapy, disease stage and PIK3CA levels. Interestingly, PIK3CA levels were high in the progressive disease state [75].

The reported carcinogenic role of PIK3CA encouraged several researchers to study its implication in breast cancer and drug resistance and its prognostic value in breast cancer. The Cancer Genome Atlas analyzed the data from the entire exomes of 510 tumors from 507 patients. They observed that only three genes had somatic mutations that occurred in more than $10 \%$ of the samples; one of these genes was PIK3CA. They found that $45 \%$ of the luminal A samples and $29 \%$ of the luminal B samples carried PIK3CA mutations, and 39\% of the HER2 (Human Epidermal Receptor 2)-enriched samples had PIK3CA mutations. Interestingly, $49 \%$ of the basal-like cancers analyzed had PIK3CA amplifications, but none of these tumors carried PIK3CA mutations [76].

Although PIK3CA mutations in ER+/HER2tumors are considered to indicate a "good prognosis", these mutations in ER+/HER2+ tumors imply tumor resistance to trastuzumab treatment [77].

One study developed a human HER2overexpressing and PIK3CA-mutant breast cancer transgenic animal. These tumors expressed elevated transcripts encoding markers for EMT and the stem cell phenotype. The signature of these tumors was consistent with the claudin-low subtype. Interesting$l y$, these tumors were able to form lung metastasis and were resistant to trastuzumab alone or in combination with lapatinib or pertuzumab [78].

A further study by Cizkova and colleagues also 
evaluated the relationship between trastuzumab treatment and PIK3CA mutation, they evaluated 80 breast tumour HER-2 positive of patients treated with trastuzumab for one year, they found that patients without mutations in PIK3CA treated with trastuzumab had a better survival compared with the group of patients with mutations in PIK3CA treated with trastuzumab, this find suggest that PIK3CA mutations are bad factor in HER-2 positive breast cancer patients receiving trastuzumab [79]. But no correlation was found in patients treated with tamoxifen [80].

Based on these findings, further studies are needed to study the potential of PIK3CA in predicting resistance to chemotherapy, in particular, to trastuzumab.

\section{Retinoic acid receptor alpha}

Another potential biomarker for predicting tamoxifen response is the Retinoic acid receptor alpha (RARA). It is known that the estrogen receptor protects breast cancer cells against programmed cell death by inducing the transcription of BCL-2, an antiapoptotic gene, which leads to cell proliferation and survival. Meanwhile, RARA and estrogen receptor (ER) have opposite effects on the proliferation and survival of breast cancer cells, as RARA inhibits proliferation and induces apoptosis [81-84]. The effects of RARA can be explained by its interaction with the ER and their shared genomic binding sites [85]. Johansson and colleagues identified a connection between endocrine resistance and RARA resistance using tamoxifen-sensitive (MCF7) and tamoxifen-resistant (LCC2) cells. They demonstrated that tamoxifen-resistant cells had higher levels of RARA. Accordingly, patients with early relapses also had higher RARA protein levels than relapse-free patients. Moreover, they used a small interfering RNA to down-regulated RARA expression, which decreased the proliferation of both MCF7 and LCC 2 cells. Based on these results, they concluded that RARA is involved in tamoxifen resistance [86]. Moreover, RARA is as a potential biomarker for predicting tamoxifen response.

\section{STAT3}

Signal transducer and activator of transcription 3 (STAT3) [87] is a downstream signaling transducer of several pathways, including interleukins, interferons, growth factors and hormones [88].

An in vitro study performed by Xiayan and colleagues showed that STAT3 is associated with tamoxifen resistance in $\mathrm{CD} 44^{+} / \mathrm{CD} 24^{-} /$low cells. STAT3 overexpression or autophosphorylation inhibits tamoxifen-mediated apoptosis, and STAT3 knockdown by siRNA abrogates tamoxifen resistance in the CD44 ${ }^{+}$CD240-low subpopulation of cells [89].

Another in vitro study using similar assays in tamoxifen-resistant cells found that STAT3 is activated in an autocrine fashion following RANTES (CCL2) activation and secretion, which results in a positive feedback loop. Interestingly, STAT3 and RANTES knockdown lead to the protein degradation of BCL-2 family proteins, indicating interdependence for these two proteins. Moreover, poly ADP ribose polymerase (PARP) levels decreased following STAT3 overexpression and RANTES-mediated signaling. The study also included immunohistochemical assays on breast cancer tissues from primary tamoxifen-treated cancer patients and the researchers observed increased levels of STAT3 and RANTES in these tissue samples [90].

Multiple studies have observed the expression of phosphorylated STAT3 (phosphor-STAT3) in several breast cancer samples. In 45 stage III invasive breast cancer samples, $22 \%$ demonstrated phosphor-STAT3 expression, which was correlated with HER2 positivity [91]. Microarray analysis of 346 node-negative and ER+ samples identified the presence of cytoplasmic and nuclear STAT3 in $69 \%$ and $23 \%$ of the samples, respectively. Cytoplasmic and nuclear phosphor-STAT3 were observed in $23 \%$ and $44 \%$ of the samples, respectively [92]. So, STAT3 might be used as a potential biomarker for predicting Tamoxifen response.

\section{Tissue inhibitor of metalloproteinase I}

Tissue inhibitor of metalloproteinase 1 (TIMP-1) is a member of the tissue inhibitors of metalloproteinases (TIMPs) family; these proteins regulate the activity of matrix metalloproteinases (MMPs). However, TIMP-1 has several additional physiological functions, including the regulation of cell proliferation, angiogenesis, and apoptosis [93, 94]. These functions imply that TIMP-1 may play a role in tumor development and growth [95].

Zhu and colleagues demonstrated that elevated expression of TIMP-1 in tumor tissue is associated with poor disease-free survival and overall survival compared to patients with low levels of TIMP-1 expression [96]. However, the potential of TIMP-1 to predict patient prognosis is controversial and is further explained below.

TIMP-1 plays an important role in the resistance to chemotherapeutic drugs that are used for the treatment of breast cancer, and this function has gained considerable attention in the research field. TIMP-1 has been associated with a decrease in sensitivity to epirubicin and paclitaxel due to increasing the degradation of cyclin B1 and by activating 
PI3K/Akt/NF-k $\beta$ signaling [97]. TIMP-1 also mediates the resistance to topoisomerase inhibitors through the upregulation and/or phosphorylation of topoisomerase [98]. Although TIMP-1 activates the PI3K-Akt pathway, which is a common pathway mediating HER2 signaling, TIMP-1 does not affect the sensitivity of HER2-targeting drugs such as trastuzumab and lapatinib in breast tumors that overexpress HER [99].

These studies suggest that TIMP-1 mediates chemotherapy resistance, and more studies are needed to investigate the potential of TIMP-1 as a predictor of drug response.

\section{Lin28}

Lin28 is a regulatory stem cell gene that was discovered in C. elegans as a heterochronic gene, and it is highly expressed in undifferentiated cells. Thus, it has been strongly implicated in tumor development in part due to its oncogenic role in the promotion of cellular proliferation and transformation [100, 101]. In a recent study, researchers found that Lin28 was overexpressed in a variety of tumors, including colon, breast, lung and cervical, therefore confirming Lin28 as an oncoprotein [102]. The underlying mechanism of Lin28 action and its oncogenic role in the intracellular environment are not completely understood. However, previous studies have shown that one possible regulatory mechanism by which this protein is able to affect normal and malignant stem cells is through posttranscriptional downregulation of microRNA Let-7, an important molecule involved in normal development and metabolism [103].

In addition, $\operatorname{Lin} 28$ is not exclusively detected in breast cancer; it is also expressed in hepatocellular carcinoma and seems to be related tumor relapse after treatment in addition to chemo- and radioresistance $[103,104]$. With respect to these findings, Lv and collaborators demonstrated that this protein was highly expressed in T47D cancer cells and strongly associated with resistance to Paclitaxel treatment via the inhibition of apoptosis. Furthermore, the same study determined that Lin28 was highly expressed in local recurrent and metastatic breast cancer. In lung and pancreatic carcinomas, a significant association between Lin28 expression and radioresistance was observed [105]. In breast cancer, data evaluating the role of this molecule are limited. Only recently have cell line studies been conducted, which demonstrated that cell lines expressing high levels of Lin28 had a higher survival rate than Lin28-downregulated cell lines exposed to radiation at doses of 2 Gy to 4 Gy [104]. In this study, the authors also demonstrated that the radioresistance occurred via the inhibition of apoptosis, which was confirmed by reduced levels of cleaved
PARP, caspase- 3 and caspase-9 in cells stably expressing Lin28. Therefore, it is plausible to hypothesize that targeting Lin28 may be an excellent therapeutic approach for those tumors that are resistance to current treatments. Targeting of Lin28 may overcome the chemo- and radioresistance phenotype of tumor cells with high sensitivity.

\section{MicroRNAs}

MicroRNAs (miRNAs) were first described in 1993 by Victor Ambros and colleagues during a study of the gene lin-14 in Caenorhabditis elegans development [106]. miRNAs are small non-coding RNA molecule, containing about 22 nucleotides. It can be found in plants, animals, and some viruses and play an important role in regulation of gene translation [107-109]. Until now, 1872 miRNAs have been identified in humans [110], some of which are implicated in diseases, including breast cancer Therefore, it might prove to be important predictors of disease progression and drug response to chemotherapy.

Expression of a single miRNA can range among different tissues types, resulting in a miRNA 'signatures'. Similarly, each tumor have a unique miRNA signature [111], which can be exploited for breast cancer diagnosis, prognosis and drug response.

Several studies have identified specific miRNA elevated in the blood and tissue of breast cancer patient. Review of Andorfer and colleagues identified miRNAs whose expressions were significantly regulated in tumors of human breast cancer patients. They found that miR-21, miR-155, miR-210, miR-29c, miR-196a, miR-213, miR-191, miR-203, miR-29b and miR-93 was significant up-regulated in tumor tissue compared with healthy subjects, while miR-125b, miR-145, miR-100, miR-10b, Let-7a-2, miR-205, miR-497 and miR-193 was downregulated The miR-31 and miR-130b were found to be both up and downregulated [112].

Despite the advances in understanding the differences in expression of miRNAs, the challenge now is comprehend what are the consequences of these differences for the improvement of clinical tools for diagnosis, prognosis and the follow up of the treatment of patients with breast cancer.

miR-195 was found to be elevated in serum breast cancer patients. This miRNA showed promising results since it could differentiate breast cancer from others cancers and from controls, in other words, it is very specific for breast cancer. Also levels of miR-195 and let-7a decreased after tumor resection, suggesting that these biomarkers are tumor-derived and could be used in breast cancer diagnosis [113, 114]. Recent meta-analyze study also pointed miR-21, miR-155, miR-222 and miR-10b as reliable candidate 
biomarkers for detection of breast cancer [115].

Some miRNA also proved to have an important role in the formation and regulation of mesenchymal stem cells, which is known to contribute for breast cancer progression. A family of microRNAs let-7 and miR-30 and, also, the microRNAs miR-200, miR-128, $\mathrm{miR}-34 \mathrm{c}$ and miR-16 were found to be down-regulated in the EMT process, whereas miR-181 family and miR-495 were found to be overexpressed [116]. Therefore, these microRNAs may be an important biomarker for prognostic and for the development of novel therapeutic strategies.

Regarding drug resistance in breast cancer, up-regulation of miR-21 has proved able to induce resistance to trastuzumab through reduction of its gene target PTEN [117, 118]. Also, it was demonstrated that estrogen can modulate miRNAs expression in breast cancer cells [119], inducing 21 miRNA, including eight let-7 family members, miRNA-98 and miRNA-21, while suppressing 7 miRNAs in MCF-7 cells. On the other hand this miRNAs may have implications in endocrine therapy resistance [120].

Considering that miRNAs are potential biomarkers for breast cancer, more studies are needed to identify and validate signatures of miRNAs for breast cancer diagnosis, prognosis or drug response.

\section{Multigene tests and molecular markers in breast cancer}

The Oncotype DX breast cancer test is a novel molecular approach performed by Genomic Health and certified by Clinical Laboratory Improvement Amendments for commercially use. It test examines a breast cancer patient's tumor tissue and analyzes a panel of 21 genes to determine a Recurrence Score within 10 years of the initial diagnosis in women with early-stage breast cancer ER positive and to predict chemotherapy benefits.

Other multigene test available commercially is MammaPrint. It test was performed by Agendia and approved by FDA (Food and Drug Administration) in 2007. It test analyzes tumor tissue for a panel of 70 genes to predict distant metastasis-free survival within 5 years in women with early-stage breast cancer both ER positive and negative. Also, the test may be useful in the chemotherapy decision.

Several studies assessed the economic impact of using multigene assays such Oncotype Dx and MammaPrint to guide adjuvant therapy decisions in breast cancer. They found that routine use of these tests had a nice cost-effectiveness, since it allowed a correct choice of chemotherapy and reduction in chemotherapy utilization [121-127].

In this study we propose potential biomarkers in breast cancer diagnosis, prognosis and drug re- sistance. These biomarkers must be extensively studied in order to identify molecular markers and create breast cancer genetic profiles. This can provide others multigenics molecular tests that could help physicians define the diagnostic and conduct the best therapeutic approach for each patient with breast cancer.

\section{CONCLUSIONS}

Despite the significant increase in the amount of research conducted on breast cancer biomarkers in the last five years, significant gaps remain that must be filled to translate this newly acquired knowledge into clinical practice.

In this review, we identify several biomarkers of particular interest for the diagnosis and prognosis of breast cancer and for predicting tumor drug responses. Of the 15 biomarkers analyzed, we found that the combination of UPA, PAI and TF, h-MAM, osteopontin, snail, twist, zeb-1, FGFR, PTEN and sirtuins could be utilized as diagnostic and prognostic predictors of breast cancer; furthermore, CYP2D6, PIK3CA, RARA, STAT3, TIMP-1 and Lin-28 have the potential to predict tumor drug response. In addition, several microRNAs were found to be related with diagnosis, prognosis and chemotherapy resistance.

An improved understanding of these potential biomarkers for the early detection and prognosis of breast cancer and for predicting chemotherapy resistance should allow better stratification of patients to reduce overtreatment or undertreatment, enhancing the prevention of relapse and increasing patient survival while reducing patient morbidity.

Thus, there is a need to validate the expression of these potential biomarkers in large patient cohorts. Additional studies using consistent methodologies are needed to define the precise value of these biomarkers for the diagnosis and prognosis of breast cancer and for their ability to predict drug resistance.

\section{ABBREVIATIONS}

ATP: Adenosine Triphosphate; BM: Bone Marrow; CSCs: Cancer Stem Cells; CYP2D6: Cytochrome P450 2D6; EM: Extensive Metabolizers; EMT: Epithelial-to-Mesenchymal Transition; ER: Estrogen Receptor; FDA: Food and Drug Administration; FFPE: Formalin-Fixed Paraffin-Embedded; FGF: Fibroblast Growth Factor; FGFR: Fibroblast Growth Factor Receptors; GCDFP-15: Gross Cystic Disease Fluid Protein-15; h-MAM: Human Mammaglobin; HER2: Human Epidermal Receptor 2; IDC: Infiltrating Ductal Carcinomas; ILC: Infiltrating Lobular Carcinomas; IM: Intermediate Metabolizers; MGBA: Mammaglobin A; MMPs: Matrix Metalloproteinases; PAI: Plasminogen Activator Inhibitor; PARP: Poly ADP Ribose Polymerase; PIK3CA: Phosphatidylinositol-4,5-bipho- 
sphonate 3-kinase; PM: Poor Metabolizers; PTEN: Phosphatase and Tensin Homolog; RARA: Retinoic Acid Receptor Alpha; RFS: Relapse-Free Survival; ROS: Reactive Oxygen Species; SERM: Selective Estrogen Receptor Modulator; SIRT: Sirtuins; SNPs: Single Nucleotide Polymorphisms; STAT3: Signal Transducer and Activator of Transcription 3; TF: Thomsen-Friedenreich; TGF $\beta$ : Transforming Growth Factor Beta; TICs: Tumor-Initiating Cells; TIMP: Tissue Inhibitor of Metalloproteinase; UM: Ultra-rapid Metabolizers; uPA: Urokinase-Dependent Plasminogen Activator System.

\section{COMPETING INTERESTS}

The authors have declared that no competing interest exists.

\section{REFERENCES}

1. Porter P. "Westernizing" women's risks? Breast cancer in lower-income countries. The New England journal of medicine. 2008; 358: 213-6. doi:10.1056/NEJMp0708307.

2. Siegel R, Naishadham D, Jemal A. Cancer statistics, 2013. CA: a cancer journal for clinicians. 2013; 63: 11-30. doi:10.3322/caac.21166.

3. Parkin DM, Bray F, Ferlay J, Pisani P. Global cancer statistics, 2002. CA: a cancer journal for clinicians. 2005; 55: 74-108.

4. Olsen O, Gotzsche PC. Cochrane review on screening for breast cancer with mammography. Lancet. 2001; 358: 1340-2. doi:10.1016/S0140-6736(01)06449-2.

5. Dundar PE, Ozmen D, Ozturk B, Haspolat G, Akyildiz F, Coban S, et al. The knowledge and attitudes of breast self-examination and mammography in a group of women in a rural area in western Turkey. BMC cancer. 2006; 6: 43. doi:10.1186/1471-2407-6-43.

6. Pisano ED, Yaffe MJ. Digital mammography. Radiology. 2005; 234: 353-62. doi:10.1148/radiol.2342030897.

7. Kamangar F, Dores GM, Anderson WF. Patterns of cancer incidence, mortality, and prevalence across five continents: defining priorities to reduce cancer disparities in different geographic regions of the world. Journal of clinical oncology : official journal of the American Society of Clinical Oncology. 2006; 24: 2137-50. doi:10.1200/JCO.2005.05.2308.

8. Coleman RE, Rubens RD. The clinical course of bone metastases from breast cancer. British journal of cancer. 1987; 55: 61-6.

9. Koenders PG, Beex LV, Kloppenborg PW, Smals AG, Benraad TJ. Human breast cancer: survival from first metastasis. Breast Cancer Study Group. Breast cancer research and treatment. 1992; 21: 173-80.

10. Jordan VC, O'Malley BW. Selective estrogen-receptor modulators and antihormonal resistance in breast cancer. Journal of clinical oncology : official journal of the American Society of Clinical Oncology. 2007; 25: 5815-24. doi:10.1200/JCO.2007.11.3886.

11. Tamoxifen for early breast cancer: an overview of the randomised trials. Early Breast Cancer Trialists' Collaborative Group. Lancet. 1998; 351: 1451-67.

12. Hrstka R, Brychtova V, Fabian P, Vojtesek B, Svoboda M. AGR2 predicts tamoxifen resistance in postmenopausal breast cancer patients. Disease markers. 2013; 35: 207-12. doi:10.1155/2013/761537.

13. Miles DW, Chan A, Dirix LY, Cortes J, Pivot X, Tomczak P, et al. Phase III study of bevacizumab plus docetaxel compared with placebo plus docetaxel for the first-line treatment of human epidermal growth factor receptor 2-negative metastatic breast cancer. Journal of clinical oncology : official journal of the American Society of Clinical Oncology. 2010; 28: 3239-47. doi:10.1200/JCO.2008.21.6457.

14. Miller K, Wang M, Gralow J, Dickler M, Cobleigh M, Perez EA, et al. Paclitaxel plus bevacizumab versus paclitaxel alone for metastatic breast cancer. The New England journal of medicine. 2007; 357: 2666-76. doi:10.1056/NEJMoa072113.

15. Longley DB, Johnston PG. Molecular mechanisms of drug resistance. The Journal of pathology. 2005; 205: 275-92. doi:10.1002/path.1706.

16. Duffy MJ. Urokinase plasminogen activator and its inhibitor, PAI-1, as prognostic markers in breast cancer: from pilot to level 1 evidence studies. Clinical chemistry. 2002; 48: 1194-7.

17. Janicke F, Schmitt M, Pache L, Ulm K, Harbeck N, Hofler H, et al. Urokinase (UPA) and its inhibitor PAI-1 are strong and independent prognostic factors in node-negative breast cancer. Breast cancer research and treatment. 1993; 24: 195-208.

18. Springer GF. T and Tn, general carcinoma autoantigens. Science. 1984; 224: 1198-206.

19. Glinsky VV, Glinsky GV, Rittenhouse-Olson K, Huflejt ME, Glinskii OV, Deutscher SL, et al. The role of Thomsen-Friedenreich antigen in adhesion of human breast and prostate cancer cells to the endothelium. Cancer research. 2001; 61: 4851-7.

20. Deutscher SL, Dickerson M, Gui G, Newton J, Holm JE, Vogeltanz-Holm N, et al. Carbohydrate antigens in nipple aspirate fluid predict the presence of atypia and cancer in women requiring diagnostic breast biopsy. BMC cancer. 2010; 10: 519. doi:10.1186/1471-2407-10-519.

21. Qin W, Gui G, Zhang K, Twelves D, Kliethermes B, Sauter ER. Proteins and carbohydrates in nipple aspirate fluid predict the presence of atypia and cancer in women requiring diagnostic breast biopsy. BMC cancer. 2012; 12: 52. doi:10.1186/1471-2407-12-52.

22. Watson MA, Fleming TP. Isolation of differentially expressed sequence tags from human breast cancer. Cancer research. 1994; 54: 4598-602.

23. Watson MA, Fleming TP. Mammaglobin, a mammary-specific member of the uteroglobin gene family, is overexpressed in human breast cancer. Cancer research. 1996; 56: 860-5.

24. Huang Y, Zhang HQ, Wang J, Song XG, Wang GH, Guan Q, et al. Cloning expression, monoclonal antibody preparation and serologic study of mammaglobin in breast cancer. Neoplasma. 2011; 58: 436-40.

25. Galvis-Jimenez JM, Curtidor H, Patarroyo MA, Monterrey P, Ramirez-Clavijo SR. Mammaglobin peptide as a novel biomarker for breast cancer detection. Cancer biology \& therapy. 2013; 14: 327-32. doi:10.4161/cbt.23614.

26. Lee GW, Kim JY, Koh EH, Kang D, Choi DS, Maeng KY, et al. Plasma human mammaglobin mRNA associated with poor outcome in patients with breast cancer. Genetics and molecular research : GMR. 2012; 11: 4034-42. doi:10.4238/2012.November.28.2.

27. Liu Y, Ma L, Liu X, Wang L. Expression of human mammaglobin as a marker of bone marrow micrometastasis in breast cancer. Experimental and therapeutic medicine. 2012; 3: 550-4. doi:10.3892/etm.2011.429.

28. Luo MH, Huang YH, Ni YB, Tsang JY, Chan SK, Shao MM, et al. Expression of mammaglobin and gross cystic disease fluid protein-15 in breast carcinomas. Human pathology. 2013; 44: 1241-50. doi:10.1016/j.humpath.2012.10.009.

29. Huo L, Zhang J, Gilcrease MZ, Gong Y, Wu Y, Zhang H, et al. Gross cystic disease fluid protein-15 and mammaglobin A expression determined by immunohistochemistry is of limited utility in triple-negative breast cancer. Histopathology. 2013; 62: 267-74. doi:10.1111/j.1365-2559.2012.04344.x.

30. Span PN, Waanders E, Manders P, Heuvel JJ, Foekens JA, Watson MA, et al. Mammaglobin is associated with low-grade, steroid receptor-positive breast tumors from postmenopausal patients, and has independent prognostic value for relapse-free survival time. Journal of clinical oncology : official journal of the American Society of Clinical Oncology. 2004; 22: 691-8. doi:10.1200/JCO.2004.01.072.

31. Senger DR, Wirth DF, Hynes RO. Transformed mammalian cells secrete specific proteins and phosphoproteins. Cell. 1979; 16: 885-93.

32. Brown LF, Papadopoulos-Sergiou A, Berse B, Manseau EJ, Tognazzi K, Perruzzi CA, et al. Osteopontin expression and distribution in human carcinomas. The American journal of pathology. 1994; 145: 610-23.

33. Weber GF, Lett GS, Haubein NC. Categorical meta-analysis of Osteopontin as a clinical cancer marker. Oncology reports. 2011; 25: 433-41. doi:10.3892/or.2010.1106

34. Thorat D, Sahu A, Behera R, Lohite K, Deshmukh S, Mane A, et al. Association of osteopontin and cyclooxygenase-2 expression with breast cancer subtypes and their use as potential biomarkers. Oncology letters. 2013; 6: 1559-64. doi:10.3892/ol.2013.1600.

35. Weber GF, Lett GS, Haubein NC. Osteopontin is a marker for cancer aggressiveness and patient survival. British journal of cancer. 2010; 103: 861-9. doi:10.1038/sj.bjc.6605834.

36. Mi Z, Bhattacharya SD, Kim VM, Guo H, Talbot LJ, Kuo PC. Osteopontin promotes CCL5-mesenchymal stromal cell-mediated breast cancer metastasis. Carcinogenesis. 2011; 32: 477-87. doi:10.1093/carcin/bgr009.

37. He B, Mirza M, Weber GF. An osteopontin splice variant induces anchorage independence in human breast cancer cells. Oncogene. 2006; 25: 2192-202. doi:10.1038/sj.onc. 1209248 .

38. Mirza M, Shaughnessy E, Hurley JK, Vanpatten KA, Pestano GA, He B, et al. Osteopontin-c is a selective marker of breast cancer. International journal of cancer Journal international du cancer. 2008; 122: 889-97. doi:10.1002/ijc.23204.

39. Pang H, Lu H, Song H, Meng Q, Zhao Y, Liu N, et al. Prognostic values of osteopontin-c, E-cadherin and beta-catenin in breast cancer. Cancer epidemiology. 2013. doi:10.1016/j.canep.2013.08.005.

40. Ortiz-Martinez F, Perez-Balaguer A, Ciprian D, Andres L, Ponce J, Adrover E, et al. Association of increased osteopontin and splice variant-c mRNA expression with HER2 and triple-negative/basal-like breast carcinomas subtypes and recurrence. Human pathology. 2013. doi:10.1016/j.humpath.2013.10.015

41. Li NY, Weber CE, Mi Z, Wai PY, Cuevas BD, Kuo PC. Osteopontin up-regulates critical epithelial-mesenchymal transition transcription factors to induce an aggressive breast cancer phenotype. Journal of the American College of Surgeons. 2013; 217: 17-26; discussion doi:10.1016/j.jamcollsurg.2013.02.025.

42. Bramwell VH, Tuck AB, Chapman JA, Anborgh PH, Postenka CO, Al-Katib $\mathrm{W}$, et al. Assessment of osteopontin in early breast cancer: correlative study in a randomised clinical trial. Breast cancer research : BCR. 2014; 16: R8. doi:10.1186/bcr3600.

43. Tenhagen M, van Diest PJ, Ivanova IA, van der Wall E, van der Groep P. Fibroblast growth factor receptors in breast cancer: expression, downstream 
effects, and possible drug targets. Endocr Relat Cancer. 2012; 19: R115-29. doi:10.1530/ERC-12-0060.

44. Hunter DJ, Kraft P, Jacobs KB, Cox DG, Yeager M, Hankinson SE, et al. A genome-wide association study identifies alleles in FGFR2 associated with risk of sporadic postmenopausal breast cancer. Nat Genet. 2007; 39: 870-4. doi:10.1038/ng2075.

45. Easton DF, Pooley KA, Dunning AM, Pharoah PD, Thompson D, Ballinger DG, et al. Genome-wide association study identifies novel breast cancer susceptibility loci. Nature. 2007; 447: 1087-93. doi:10.1038/nature05887.

46. Kim S, Dubrovska A, Salamone RJ, Walker JR, Grandinetti KB, Bonamy GM, et al. FGFR2 promotes breast tumorigenicity through maintenance of breast tumor-initiating cells. PloS one. 2013; 8: e51671. doi:10.1371/journal.pone.0051671.

47. Zhu X, Asa SL, Ezzat S. Histone-acetylated control of fibroblast growth factor receptor 2 intron 2 polymorphisms and isoform splicing in breast cancer. Mol Endocrinol. 2009; 23: 1397-405. doi:10.1210/me.2009-0071.

48. Moffa AB, Tannheimer SL, Ethier SP. Transforming potential of alternatively spliced variants of fibroblast growth factor receptor 2 in human mammary epithelial cells. Mol Cancer Res. 2004; 2: 643-52.

49. Steck PA, Pershouse MA, Jasser SA, Yung WK, Lin H, Ligon AH, et al. Identification of a candidate tumour suppressor gene, MMAC1, at chromosome 10q23.3 that is mutated in multiple advanced cancers. Nat Genet. 1997; 15: 356-62. doi:10.1038/ng0497-356.

50. Tokunaga E, Oki E, Kimura Y, Yamanaka T, Egashira A, Nishida K, et al. Coexistence of the loss of heterozygosity at the PTEN locus and HER2 overexpression enhances the Akt activity thus leading to a negative progesterone receptor expression in breast carcinoma. Breast Cancer Res Treat. 2007; 101: 249-57. doi:10.1007/s10549-006-9295-8.

51. Nakajima H, Sakaguchi K, Fujiwara I, Mizuta M, Tsuruga M, Magae J, et al. Apoptosis and inactivation of the PI3-kinase pathway by tetrocarcin A in breast cancers. Biochem Biophys Res Commun. 2007; 356: 260-5. doi:10.1016/j.bbrc.2007.02.136.

52. Milovanovic Z, Dzodic R, Susnjar S, Plesinac-Karapandzic V, Juranic Z, Tatic S. PTEN protein expression in postmenopausal steroid receptor positive early breast cancer patients treated with adjuvant tamoxifen. J BUON. 2011; 16: 46-51.

53. Zhang HY, Liang F, Jia ZL, Song ST, Jiang ZF. PTEN mutation, methylation and expression in breast cancer patients. Oncol Lett. 2013; 6: 161-8. doi:10.3892/ol.2013.1331.

54. Ashraf N, Zino S, Macintyre A, Kingsmore D, Payne AP, George WD, et al. Altered sirtuin expression is associated with node-positive breast cancer. British journal of cancer. 2006; 95: 1056-61. doi:10.1038/sj.bjc.6603384.

55. Verdin E, Hirschey MD, Finley LW, Haigis MC. Sirtuin regulation of mitochondria: energy production, apoptosis, and signaling. Trends in biochemical sciences. 2010; 35: 669-75. doi:10.1016/j.tibs.2010.07.003.

56. Finley LW, Carracedo A, Lee J, Souza A, Egia A, Zhang J, et al. SIRT3 opposes reprogramming of cancer cell metabolism through HIF1alpha destabilization. Cancer cell. 2011; 19: 416-28. doi:10.1016/j.ccr.2011.02.014

57. Kim HS, Patel K, Muldoon-Jacobs K, Bisht KS, Aykin-Burns N, Pennington JD, et al. SIRT3 is a mitochondria-localized tumor suppressor required for maintenance of mitochondrial integrity and metabolism during stress. Cancer cell. 2010; 17: 41-52. doi:10.1016/j.ccr.2009.11.023.

58. Singh A, Settleman J. EMT, cancer stem cells and drug resistance: an emerging axis of evil in the war on cancer. Oncogene. 2010; 29: 4741-51. doi:10.1038/onc.2010.215.

59. Reya T, Morrison SJ, Clarke MF, Weissman IL. Stem cells, cancer, and cancer stem cells. Nature. 2001; 414: 105-11. doi:10.1038/35102167.

60. Chaffer CL, Brennan JP, Slavin JL, Blick T, Thompson EW, Williams ED. Mesenchymal-to-epithelial transition facilitates bladder cancer metastasis: role of fibroblast growth factor receptor-2. Cancer Res. 2006; 66: 11271-8. doi:10.1158/0008-5472.CAN-06-2044.

61. Castano Z, Fillmore CM, Kim CF, McAllister SS. The bed and the bugs: interactions between the tumor microenvironment and cancer stem cells. Semin Cancer Biol. 2012; 22: 462-70. doi:10.1016/j.semcancer.2012.04.006.

62. Ling LJ, Wang S, Liu XA, Shen EC, Ding Q, Lu C, et al. A novel mouse model of human breast cancer stem-like cells with high CD44+CD24-/lower phenotype metastasis to human bone. Chin Med J (Engl). 2008; 121: 1980-6.

63. Blanco MJ, Moreno-Bueno G, Sarrio D, Locascio A, Cano A, Palacios J, et al. Correlation of Snail expression with histological grade and lymph node status in breast carcinomas. Oncogene. 2002; 21: 3241-6. doi:10.1038/sj.onc.1205416.

64. Tran DD, Corsa CA, Biswas H, Aft RL, Longmore GD. Temporal and spatial cooperation of Snail1 and Twist1 during epithelial-mesenchymal transition predicts for human breast cancer recurrence. Mol Cancer Res. 2011; 9: 1644-57. doi:10.1158/1541-7786.MCR-11-0371.

65. Chaffer CL, Marjanovic ND, Lee T, Bell G, Kleer CG, Reinhardt F, et al. Poised chromatin at the ZEB1 promoter enables breast cancer cell plasticity and enhances tumorigenicity. Cell. 2013; 154: 61-74. doi:10.1016/j.cell.2013.06.005.

66. Early Breast Cancer Trialists' Collaborative G. Effects of chemotherapy and hormonal therapy for early breast cancer on recurrence and 15-year survival: an overview of the randomised trials. Lancet. 2005; 365: 1687-717. doi:10.1016/S0140-6736(05)66544-0.

67. Desta Z, Ward BA, Soukhova NV, Flockhart DA. Comprehensive evaluation of tamoxifen sequential biotransformation by the human cytochrome P450 system in vitro: prominent roles for CYP3A and CYP2D6. The Journal of pharmacology and experimental therapeutics. 2004; 310: 1062-75. doi:10.1124/jpet.104.065607.

68. Johnson MD, Zuo H, Lee KH, Trebley JP, Rae JM, Weatherman RV, et al. Pharmacological characterization of 4-hydroxy-N-desmethyl tamoxifen, a novel active metabolite of tamoxifen. Breast cancer research and treatment. 2004; 85: 151-9. doi:10.1023/B:BREA.0000025406.31193.e8.

69. Beverage JN, Sissung TM, Sion AM, Danesi R, Figg WD. CYP2D6 polymorphisms and the impact on tamoxifen therapy. Journal of pharmaceutical sciences. 2007; 96: 2224-31. doi:10.1002/jps.20892.

70. Rodriguez-Antona C, Ingelman-Sundberg M. Cytochrome P450 pharmacogenetics and cancer. Oncogene. 2006; 25: 1679-91. doi:10.1038/sj.onc.1209377.

71. Lim JS, Chen XA, Singh O, Yap YS, Ng RC, Wong NS, et al. Impact of CYP2D6, CYP3A5, CYP2C9 and CYP2C19 polymorphisms on tamoxifen pharmacokinetics in Asian breast cancer patients. British journal of clinical pharmacology. 2011; 71: 737-50. doi:10.1111/j.1365-2125.2011.03905.x.

72. Zafra-Ceres M, de Haro T, Farez-Vidal E, Blancas I, Bandres F, de Duenas EM, et al. Influence of CYP2D6 polymorphisms on serum levels of tamoxifen metabolites in Spanish women with breast cancer. International journal of medical sciences. 2013; 10: 932-7. doi:10.7150/ijms.5708.

73. Regan MM, Leyland-Jones B, Bouzyk M, Pagani O, Tang W, Kammler R, et al. CYP2D6 genotype and tamoxifen response in postmenopausal women with endocrine-responsive breast cancer: the breast international group 1-98 trial. Journal of the National Cancer Institute. 2012; 104: 441-51. doi:10.1093/jnci/djs125.

74. German S, Aslam HM, Saleem S, Raees A, Anum T, Alvi AA, et al. Carcinogenesis of PIK3CA. Hered Cancer Clin Pract. 2013; 11: 5. doi:10.1186/1897-4287-11-5.

75. Dawson SJ, Tsui DW, Murtaza M, Biggs H, Rueda OM, Chin SF, et al. Analysis of circulating tumor DNA to monitor metastatic breast cancer. N Engl J Med. 2013; 368: 1199-209. doi:10.1056/NEJMoa1213261.

76. Cancer Genome Atlas N. Comprehensive molecular portraits of human breast tumours. Nature. 2012; 490: 61-70. doi:10.1038/nature11412.

77. $\mathrm{Fu} \mathrm{X}$, Osborne $\mathrm{CK}$, Schiff R. Biology and therapeutic potential of PI3K signaling in ER+/HER2-negative breast cancer. Breast. 2013. doi:10.1016/j.breast.2013.08.001.

78. Hanker AB, Pfefferle AD, Balko JM, Kuba MG, Young CD, Sanchez V, et al. Mutant PIK3CA accelerates HER2-driven transgenic mammary tumors and induces resistance to combinations of anti-HER2 therapies. Proc Natl Acad Sci U S A. 2013; 110: 14372-7. doi:10.1073/pnas.1303204110.

79. Cizkova M, Dujaric ME, Lehmann-Che J, Scott V, Tembo O, Asselain B, et al. Outcome impact of PIK3CA mutations in HER2-positive breast cancer patients treated with trastuzumab. British journal of cancer. 2013; 108: 1807-9. doi:10.1038/bjc.2013.164.

80. Ramirez-Ardila DE, Helmijr JC, Look MP, Lurkin I, Ruigrok-Ritstier K, van Laere S, et al. Hotspot mutations in PIK3CA associate with first-line treatment outcome for aromatase inhibitors but not for tamoxifen. Breast cancer research and treatment. 2013; 139: 39-49. doi:10.1007/s10549-013-2529-7.

81. Ciocca DR, Fanelli MA. Estrogen receptors and cell proliferation in breast cancer. Trends in endocrinology and metabolism: TEM. 1997; 8: 313-21.

82. Teixeira C, Reed JC, Pratt MA. Estrogen promotes chemotherapeutic drug resistance by a mechanism involving $\mathrm{Bcl}-2$ proto-oncogene expression in human breast cancer cells. Cancer research. 1995; 55: 3902-7.

83. Niederreither K, Dolle P. Retinoic acid in development: towards an integrated view. Nature reviews Genetics. 2008; 9: 541-53, doi:10.1038/nrg2340.

84. Liu R, Takayama S, Zheng Y, Froesch B, Chen GQ, Zhang X, et al. Interaction of BAG-1 with retinoic acid receptor and its inhibition of retinoic acid-induced apoptosis in cancer cells. The Journal of biological chemistry. 1998; 273: 16985-92.

85. Hua S, Kittler R, White KP. Genomic antagonism between retinoic acid and estrogen signaling in breast cancer. Cell. 2009; 137: 1259-71. doi:10.1016/j.cell.2009.04.043.

86. Johansson HJ, Sanchez BC, Mundt F, Forshed J, Kovacs A, Panizza E, et al. Retinoic acid receptor alpha is associated with tamoxifen resistance in breast cancer. Nature communications. 2013; 4: 2175. doi:10.1038/ncomms3175.

87. Akira S, Nishio $\mathrm{Y}$, Inoue M, Wang XJ, Wei S, Matsusaka T, et al. Molecular cloning of APRF, a novel IFN-stimulated gene factor 3 p91-related transcription factor involved in the gp130-mediated signaling pathway. Cell. 1994; 77: 63-71.

88. Subramaniam A, Shanmugam MK, Perumal E, Li F, Nachiyappan A, Dai X, et al. Potential role of signal transducer and activator of transcription (STAT) 3 signaling pathway in inflammation, survival, proliferation and invasion of hepatocellular carcinoma. Biochim Biophys Acta. 2013; 1835: 46-60. doi:10.1016/j.bbcan.2012.10.002

89. Wang $X$, Wang $G$, Zhao $Y$, Liu $X$, Ding $Q$, Shi J, et al. STAT3 mediates resistance of CD44(+)CD24(-/low) breast cancer stem cells to tamoxifen in vitro. J Biomed Res. 2012; 26: 325-35. doi:10.7555/JBR.26.20110050.

90. Yi EH, Lee CS, Lee JK, Lee YJ, Shin MK, Cho CH, et al. STAT3-RANTES autocrine signaling is essential for tamoxifen resistance in human breast cancer cells. Mol Cancer Res. 2013; 11: 31-42. doi:10.1158/1541-7786.MCR-12-0217.

91. Diaz N, Minton S, Cox C, Bowman T, Gritsko T, Garcia R, et al. Activation of stat3 in primary tumors from high-risk breast cancer patients is associated with elevated levels of activated SRC and survivin expression. Clin Cancer Res. 2006; 12: 20-8. doi:10.1158/1078-0432.CCR-04-1749. 
92. Dolled-Filhart M, Camp RL, Kowalski DP, Smith BL, Rimm DL. Tissue microarray analysis of signal transducers and activators of transcription 3 (Stat3) and phospho-Stat3 (Tyr705) in node-negative breast cancer shows nuclear localization is associated with a better prognosis. Clin Cancer Res. 2003; 9: 594-600.

93. Egeblad M, Werb Z. New functions for the matrix metalloproteinases in cancer progression. Nature reviews Cancer. 2002; 2: 161-74. doi:10.1038/nrc745.

94. Stetler-Stevenson WG. Tissue inhibitors of metalloproteinases in cell signaling: metalloproteinase-independent biological activities. Science signaling. 2008; 1: re6. doi:10.1126/scisignal.127re6.

95. Wurtz SO, Schrohl AS, Sorensen NM, Lademann U, Christensen IJ, Mouridsen $\mathrm{H}$, et al. Tissue inhibitor of metalloproteinases- 1 in breast cancer. Endocrine-related cancer. 2005; 12: 215-27. doi:10.1677/erc.1.00719.

96. Zhu D, Zha X, Hu M, Tao A, Zhou H, Zhou X, et al. High expression of TIMP-1 in human breast cancer tissues is a predictive of resistance to paclitaxel-based $\begin{array}{llll}\text { chemotherapy. Medical oncology. 2012; 29: 3207-15. } & \text {. }\end{array}$ doi:10.1007/s12032-012-0239-3.

97. Fu ZY, Lv JH, Ma CY, Yang DP, Wang T. Tissue inhibitor of metalloproteinase-1 decreased chemosensitivity of MDA-435 breast cancer cells to chemotherapeutic drugs through the PI3K/AKT/NF-small ka, CyrillicB pathway. Biomedicine \& pharmacotherapy $=$ Biomedecine \& pharmacotherapie. 2011; 65: 163-7. doi:10.1016/j.biopha.2011.02.004.

98. Hekmat O, Munk S, Fogh L, Yadav R, Francavilla C, Horn H, et al. TIMP-1 Increases Expression and Phosphorylation of Proteins Associated with Drug Resistance in Breast Cancer Cells. Journal of proteome research. 2013; 12: 4136-51. doi:10.1021/pr400457u.

99. Deng X, Fogh L, Lademann U, Jensen V, Stenvang J, Yang H, et al. TIMP-1 overexpression does not affect sensitivity to HER2-targeting drugs in the HER2-gene-amplified SK-BR-3 human breast cancer cell line. Tumour biology : the journal of the International Society for Oncodevelopmental Biology and Medicine. 2013; 34: 1161-70. doi:10.1007/s13277-013-0659-5.

100. Viswanathan SR, Daley GQ. Lin28: A microRNA regulator with a macro role. Cell. 2010; 140: 445-9. doi:10.1016/j.cell.2010.02.007.

101. Malik F, Korkaya H, Clouthier SG, Wicha MS. Lin28 and HER2: two stem cell regulators conspire to drive aggressive breast cancer. Cell cycle. 2012; 11: 2780-1. doi:10.4161/cc.21395.

102. Viswanathan SR, Powers JT, Einhorn W, Hoshida Y, Ng TL, Toffanin S, et al. Lin28 promotes transformation and is associated with advanced human malignancies. Nature genetics. 2009; 41: 843-8. doi:10.1038/ng.392.

103. Lv K, Liu L, Wang L, Yu J, Liu X, Cheng Y, et al. Lin28 mediates paclitaxel resistance by modulating p21, $\mathrm{Rb}$ and Let-7a miRNA in breast cancer cells. PloS one. 2012; 7: e40008. doi:10.1371/journal.pone.0040008.

104. Wang L, Yuan C, Lv K, Xie S, Fu P, Liu X, et al. Lin28 mediates radiation resistance of breast cancer cells via regulation of caspase, H2A.X and Let-7 signaling. PloS one. 2013; 8: e67373. doi:10.1371/journal.pone.0067373.

105. Oh JS, Kim JJ, Byun JY, Kim IA. Lin28-let7 modulates radiosensitivity of human cancer cells with activation of K-Ras. International journal of radiation oncology, biology, physics. 2010; 76: 5-8. doi:10.1016/j.ijrobp.2009.08.028.

106. Lee RC, Feinbaum RL, Ambros V. The C. elegans heterochronic gene lin-4 encodes small RNAs with antisense complementarity to lin-14. Cell. 1993; 75: 843-54.

107. Bartel DP. MicroRNAs: genomics, biogenesis, mechanism, and function. Cell. 2004; 116: 281-97.

108. Bartel DP. MicroRNAs: target recognition and regulatory functions. Cell. 2009; 136: 215-33, doi:10.1016/j.cell.2009.01.002.

109. McDaneld TG. MicroRNA: mechanism of gene regulation and application to livestock. Journal of animal science. 2009; 87: E21-8. doi:10.2527/jas.2008-1303.

110. Manchester FoLSatUo. Homo sapiens miRNAs.

111. Lu J, Getz G, Miska EA, Alvarez-Saavedra E, Lamb J, Peck D, et al. MicroRNA expression profiles classify human cancers. Nature. 2005; 435: 834-8. doi:10.1038/nature03702.

112. Andorfer CA, Necela BM, Thompson EA, Perez EA. MicroRNA signatures: clinical biomarkers for the diagnosis and treatment of breast cancer. Trends in molecular medicine. 2011; 17: 313-9. doi:10.1016/j.molmed.2011.01.006.

113. Heneghan HM, Miller N, Lowery AJ, Sweeney KJ, Newell J, Kerin MJ. Circulating microRNAs as novel minimally invasive biomarkers for breast $\begin{array}{lll}\text { cancer. Annals of surgery. 2010; 251: 499-505. } & \text {; }\end{array}$ doi:10.1097/SLA.0b013e3181cc939f.

114. Heneghan HM, Miller N, Kelly R, Newell J, Kerin MJ. Systemic miRNA-195 differentiates breast cancer from other malignancies and is a potential biomarker for detecting noninvasive and early stage disease. The oncologist. 2010; 15: 673-82. doi:10.1634/theoncologist.2010-0103.

115. Lv M, Zhu X, Chen W, Zhao J, Tang J. Searching for candidate microRNA biomarkers in detection of breast cancer: a meta-analysis. Cancer biomarkers : section A of Disease markers. 2013; 13: 395-401. doi:10.3233/CBM-130379.

116. Schwarzenbacher D, Balic $M$, Pichler $M$. The role of microRNAs in breast cancer stem cells. International journal of molecular sciences. 2013; 14: 14712-23. doi:10.3390/ijms140714712.

117. Gong C, Yao Y, Wang Y, Liu B, Wu W, Chen J, et al. Up-regulation of miR-21 mediates resistance to trastuzumab therapy for breast cancer. The Journal of biological chemistry. 2011; 286: 19127-37. doi:10.1074/jbc.M110.216887.

118. Hong L, Han Y, Zhang Y, Zhang H, Zhao Q, Wu K, et al. MicroRNA-21: a therapeutic target for reversing drug resistance in cancer. Expert opinion on therapeutic targets. 2013; 17: 1073-80. doi:10.1517/14728222.2013.819853.
119. McCafferty MP, McNeill RE, Miller N, Kerin MJ. Interactions between the estrogen receptor, its cofactors and microRNAs in breast cancer. Breast cancer research and treatment. 2009; 116: 425-32. doi:10.1007/s10549-009-0429-7.

120. Bhat-Nakshatri P, Wang G, Collins NR, Thomson MJ, Geistlinger TR, Carroll JS, et al. Estradiol-regulated microRNAs control estradiol response in breast cancer cells. Nucleic acids research. 2009; 37: 4850-61. doi:10.1093/nar/gkp500.

121. Rouzier R, Pronzato P, Chereau E, Carlson J, Hunt B, Valentine WJ. Multigene assays and molecular markers in breast cancer: systematic review of health economic analyses. Breast cancer research and treatment. 2013; 139: 621-37. doi:10.1007/s10549-013-2559-1.

122. Cosler LE, Lyman GH. Economic analysis of gene expression profile data to guide adjuvant treatment in women with early-stage breast cancer. Cancer investigation. 2009; 27: 953-9. doi:10.3109/07357900903275217.

123. Bacchi CE, Prisco F, Carvalho FM, Ojopi EB, Saad ED. Potential economic impact of the 21-gene expression assay on the treatment of breast cancer in Brazil. Revista da Associacao Medica Brasileira. 2010; 56: 186-91.

124. Klang SH, Hammerman A, Liebermann N, Efrat N, Doberne J, Hornberger J. Economic implications of 21-gene breast cancer risk assay from the perspective of an Israeli-managed health-care organization. Value in health : the journal of the International Society for Pharmacoeconomics and Outcomes Research. 2010; 13: 381-7. doi:10.1111/j.1524-4733.2010.00724.x.

125. Kondo M, Hoshi SL, Yamanaka T, Ishiguro H, Toi M. Economic evaluation of the 21-gene signature (Oncotype DX) in lymph node-negative/positive, hormone receptor-positive early-stage breast cancer based on Japanese validation study (JBCRG-TR03). Breast cancer research and treatment. 2011; 127: 739-49. doi:10.1007/s10549-010-1243-y.

126. Chen E, Tong KB, Malin JL. Cost-effectiveness of 70-gene MammaPrint signature in node-negative breast cancer. The American journal of managed care. 2010; 16: e333-42.

127. Retel VP, Joore MA, Knauer M, Linn SC, Hauptmann M, Harten WH. Cost-effectiveness of the 70-gene signature versus St. Gallen guidelines and Adjuvant Online for early breast cancer. European journal of cancer. 2010; 46: 1382-91. doi:10.1016/j.ejca.2010.02.035. 